\title{
Cytological and molecular characterization of three gametoclones of Citrus clementina
}

\author{
Maria Antonietta Germana', Pablo Aleza ${ }^{9}$, Esther Carrera², Chunxian Chen ${ }^{3,10}$, Benedetta Chiancone ${ }^{1}$, \\ Gilles Costantino ${ }^{7}$, Dominique Dambier ${ }^{4}$, Xiuxin Deng ${ }^{5}$, Claire T Federici ${ }^{6}$, Yann Froelicher ${ }^{4}$, Wenwu Guo ${ }^{5}$, \\ Victoria Ibáñez ${ }^{2}$, José Juárez ${ }^{9}$, Kevin Kwok ${ }^{6}$, François Luro ${ }^{7}$, Marcos A Machado ${ }^{8}$, Miguel Angel Naranjo², \\ Luis Navarro ${ }^{9}$, Patrick Ollitrault ${ }^{4}$, Gabino Ríos ${ }^{2}$, Mikeal L Roose ${ }^{6}$, Manuel Talon ${ }^{2}$, Qiang X $\mathrm{u}^{5}$ and Fred G Gmitter $\mathrm{Jr}^{3^{*}}$
}

\begin{abstract}
Background: Three gametoclonal plants of Citrus clementina Hort. ex Tan., cV. Nules, designated ESP, FRA, and ITA (derived from three labs in Spain, France, and Italy, respectively), were selected for cytological and molecular characterization in order to elucidate genomic rearrangements provoked by haploidization. The study included comparisons of their ploidy, homozygosity, genome integrity, and gene dosage, using chromosome counting, flow cytometry, SSR marker genotyping, and array-Comparative Genomic Hybridization (array-CGH).

Results: Chromosome counting and flow cytometry revealed that ESP and FRA were haploid, but ITA was tri-haploid. Homozygous patterns, represented by a single peak (allele), were observed among the three plants at almost all SSR loci distributed across the entire diploid donor genome. Those few loci with extra peaks visualized as output from automated sequencing runs, generally low or ambiguous, might result from amplicons of paralogous members at the locus, non-specific sites, or unexpected recombinant alleles. No new alleles were found, suggesting the genomes remained stable and intact during gametogenesis and regeneration. The integrity of the haploid genome also was supported by array-CGH studies, in which genomic profiles were comparable to the diploid control.

Conclusions: The presence of few gene hybridization abnormalities, corroborated by gene dosage measurements, were hypothetically due to the segregation of hemizygous alleles and minor genomic rearrangements occurring during the haploidization procedure. In conclusion, these plants that are valuable genetic and breeding materials contain completely homozygous and essentially intact genomes.
\end{abstract}

Keywords: Anther culture, Gynogenesis, Gametoclonal variation, Genome sequencing

\section{Background}

Haploid plants or their derivatives, e.g. doubled haploid (DH) or tri-haploid (TH), are valuable in conventional breeding and genetic studies. However, most Citrus genomes are highly heterozygous, and it is practically impossible to develop homozygous lines through conventional hybridization, due to sexual incompatibility, nucellar embryony, severe inbreeding depression, and long juvenility. Gametic embryogenesis is a single-step approach to

\footnotetext{
* Correspondence: fgmitter@ufl.edu

${ }^{3}$ University of Florida, Citrus Research and Education Center, Lake Alfred, FL, USA

Full list of author information is available at the end of the article
}

produce homozygous clones from heterozygous parents [1-7], from which most Citrus haploids were generated.

In situ parthenogenesis induced by irradiated pollen, followed by in vitro embryo culture has been reported in Citrus [8-11]. Haploid plantlets have been recovered by anther culture from Poncirus trifoliata L. Raf. [12] and C. madurensis Lour. [13]. A doubled haploid plantlet has been obtained from the hybrid No. 14 of C. ichangensis $\times$ C. reticulata [14]. Haploid plantlets and highly embryogenic haploid calli were recovered from C. clementina Hort. ex Tan. [15-17]. Haploid, but albino embryos, arose from cultures of 'Mapo' tangelo (C. deliciosa $\times$ C. paradisi) [18]. In other reports, haploid and diploid calli, embryos and leafy structures, but no green plants, were produced
C Biomed Central

(c) 2013 Germana et al.; licensee BioMed Central Ltd. This is an Open Access article distributed under the terms of the Creative Commons Attribution License (http://creativecommons.org/licenses/by/2.0), which permits unrestricted use, distribution, and reproduction in any medium, provided the original work is properly cited. 
from culture of C. limon L. Burm. f. anthers [19]. Haploid embryos of Clausena excavata [20] and homozygous short-lived plantlets of Rhode Red Valencia sweet orange [21] have also been reported.

The objective of this work was to elucidate the effect of haploidization in the genome structure of three different gametoclonal plants of Citrus clementina Hort. ex Tan., cv. Nules. To compare their genomes, the three gametoclones obtained by gynogenesis or by pollen embryogenesis, were freely provided by research groups in Spain (Navarro), France (Ollitrault), and Italy (Germanà). The tissues and DNA samples from the three candidate plants have been analyzed and characterized using various technologies and methods by laboratories in several institutions worldwide to assure that they are free of large deletions or other defects, as well as to confirm their homozygosity (mono-allelic at any locus analyzed). Specifically, candidate tree chromosome numbers were verified for their ploidy levels. The candidate genomes were evaluated using genomic or EST-derived SSR markers and microarray technology. The collaborative results on the three materials are reported here in detail.

\section{Methods}

\section{Plant material}

Three gametoclonal plants, designated ESP, FRA, and ITA respectively acquired in the lab of Navarro (Spain), Ollitrault (France), and Germanà (Italy), were all derived from Citrus clementina Hort. ex Tan., cv. Nules and preliminarily shown to be homozygous based on some selected loci. They were obtained by in situ parthenogenesis induced by irradiated pollen followed by in vitro embryo culture, or by pollen embryogenesis. Specifically, ESP was through in vivo-induced gynogenesis by pollination of Nules Clementine with irradiated pollen of Fortune mandarin followed by in vitro embryo rescue [22], FRA also through gynogenesis by pollination in the field with irradiated Meyer lemon (Citrus meyeri Y. Tan.) pollen [11], and ITA was obtained through anther culture of C. clementina cv. Nules [15,17]. ESP was previously characterized as a haploid [22]. All three plants were much less vigorous than the heterozygous mother plant, as revealed by leaf size and growth habit (Additional file 1: Figure S1). Samples from all three plants were sent to the respective laboratories of the collaborators for the specific analyses to which each group had committed.

\section{Chromosome number determination}

Root- and shoot-tip chromosome counting was conducted using DAPI (4,6-diamidino-2-phenylindole) and hematoxylin staining techniques [23], respectively.

\section{SSR genotyping and analysis}

SSR markers presumably or evidently heterozygous in the diploid Clementine control were selected for genotyping and analysis to determine if the three plant genomes were homozygous and complete at the various loci examined. Five laboratories were involved (Table 1), and primer sets, amplification conditions, and separation methods were summarized. At CIRAD, INRA, and IVIA, amplifications were performed according to Froelicher et al. [24] in a thermocycler (PTC-200, MJ Research) using $10 \mathrm{ng}$ of citrus DNA, $0.2 \mu \mathrm{M}$ of each primer and 0.8 unit of Taq polymerase (Goldstar, Eurogentec). The annealing temperature for all primers was $55^{\circ} \mathrm{C}$. The 39 EST-SSR primers used in this study were selected based on their representation of each of the linkage groups defined in a Clementine genetic map [25,26]. At the University of Florida - CREC, 40 EST-SSR markers, likewise well distributed among the linkage groups in the diploid Clementine genetic map [25], were chosen for genotyping. All the genotyping, computing, and scoring procedures were previously described in detail [27,28]; similar methods were used at CCSM [29]. At the University of California, Riverside (UCR) amplifications were performed essentially according to Barkley et al. [30], except that PCR products were labeled by adding a 19 or 20-base M13 tail to the $5^{\prime}$ end of one sequencespecific primer and including an M13F or M13R primer carrying a dye label (LiCor IRD700 or IRD800) in each PCR reaction [31].

\section{Array-CGH analysis}

Array-CGH was performed as described in Rios et al. [32]. Genomic DNA was isolated from leaves [33]. Four Cy3- or Cy5-labelled samples from each gametoclonal plant were co-profiled on four $20 \mathrm{~K}$ Citrus cDNA microarrays containing 21240 EST, using Cy5- or Cy3labelled control genomic DNA, respectively [34]. To prepare labelled probes, Cy3- or Cy5-dCTP fluorescent

\begin{tabular}{|c|c|c|c|c|c|c|c|}
\hline $\begin{array}{l}\text { No. of PCR } \\
\text { products in } \\
\text { diploid } \\
\text { clementine }\end{array}$ & $\begin{array}{l}\text { No. of PCR } \\
\text { products in } \\
\text { ITA, ESP, } \\
\text { and FRA }\end{array}$ & CREC & INRA & CCSM & $\begin{array}{l}\text { CIRAD/ } \\
\text { IVIA }\end{array}$ & UCR & Total \\
\hline 1 & 1 & 0 & 0 & 0 & 0 & 45 & 45 \\
\hline 1 & 0 or 1 & 0 & 0 & 0 & 0 & 2 & 2 \\
\hline 2 & 1 & 40 & 39 & 9 & 41 & 57 & 186 \\
\hline 2 & 1 or 2 & 0 & 0 & 1 & 0 & 3 & 4 \\
\hline Total markers & & 40 & 39 & 10 & 41 & 107 & 237 \\
\hline Anomalous & & 0 & 0 & 1 & 0 & 5 & 6 \\
\hline
\end{tabular}


nucleotides (Amersham Biosciences) were incorporated directly in control and gametoclonal genomic DNA $(2 \mu \mathrm{g})$ using BioPrime Array CGH Genomic Labelling System (Invitrogen). Each pair of purified Cy5 and Cy3 probes (about $50 \mu \mathrm{l}$ each) was combined and mixed with $30 \mu \mathrm{g}$ Cot-1 DNA (Invitrogen), $100 \mu \mathrm{g}$ yeast tRNA (Invitrogen), and $346 \mu \mathrm{TE}$ buffer $\mathrm{pH}$ 7.4. Samples were concentrated with a microcon YM-30 filter (Millipore), and SSC buffer and SDS were added to reach a final volume of $60 \mu \mathrm{l}$ containing $3.4 \times$ SSC and $0.3 \%$ SDS. For microarray hybridization, the probe mixture was denatured by heating at $97^{\circ} \mathrm{C}$ for 5 minutes, and immediately incubated at $37^{\circ} \mathrm{C}$ during 30 minutes to block repetitive DNA sequences. Hybridization mixture was applied to a $37^{\circ} \mathrm{C}$ pre-warmed hybrid-slip (Sigma), and a pre-warmed array slide was lowered onto the mix. Microarrays were hybridized in darkness at $65^{\circ} \mathrm{C}$ overnight (16-20 hours) using a glass array cassette following manufacturer's instructions (Ambion). To prevent evaporation of hybridization solution during incubation, $5 \mu$ l of $3 \times$ SCC were poured into the reservoir inside the cassette chamber. Following hybridization, microarray slides were placed in a rack and the cover slip removed by 10 minutes immersion in a washing chamber containing $2 \times$ SSC and $0.03 \%$ SDS at room temperature (RT). Microarray slides were passed through a series of washes on a shaking platform. Wash series were as follow: $2 \times$ SSC, $0.03 \%$ SDS for $5 \mathrm{~min}$ at $65^{\circ} \mathrm{C}$, followed by $1 \times \mathrm{SSC}$ for $5 \mathrm{~min}$ at $\mathrm{RT}$, and $3 \times 15 \mathrm{~min}$ washes in $0.2 \times$ SSC at RT. Microarray slides were dried by centrifugation for $5 \mathrm{~min}$ at $300 \mathrm{rpm}$. Arrays were immediately scanned at $5 \mu \mathrm{m}$. Cy3 and Cy5 fluorescence intensity was collected by using a ScanArray Gx (Perkin Elmer). The resulting images were overlaid and spots identified by the ScanArray Express program (Perkin Elmer). Spot quality was first measured by the signal-to-background method with parameters lower limit (200) and multiplier (2), and subsequently confirmed by visual test. The results were normalized for labeling and detection efficiencies of the two fluorescence dyes, prior to determining differential gene expression between haploid and diploid citrus samples. Intensities of selected spots were transformed locally weighted linear regression (LOWESS) method. Genespring vs 7.3 software (Agilent, http.//www.agilent. com) was used to normalize values for each gene and for data analysis. Differentially regulated genes were ranked on the basis of signal intensity, normalized ratio, flag value and variance across 4 replicate experiments. Filtered genes identified to be differentially expressed by haploid/diploid signals lower than 0.3 with a P-value not higher than 0.05 were considered for subsequent gene dosage measurements. One-way ANOVA, parametric test without the assumption of equal variances was used to define differentially expressed genes.

\section{Gene dosage measurement}

Quantitative real-time PCR was performed on a LightCycler 2.0 instrument (Roche), using the LightCycler FastStart DNA MasterPLUS SYBR Green I kit (Roche). Reaction composition and conditions followed manufacturer's instructions. Each individual PCR reaction contained $2 \mathrm{ng}$ of genomic DNA from gametoclonal or diploid control [33]. Cycling protocol consisted of $10 \mathrm{~min}$ at $95^{\circ} \mathrm{C}$ for preincubation, then 40 cycles of $10 \mathrm{sec}$ at $95^{\circ} \mathrm{C}$ for denaturation, $10 \mathrm{sec}$ at $60^{\circ} \mathrm{C}$ for annealing and $10-25 \mathrm{sec}$ at $72^{\circ} \mathrm{C}$ for extension. Fluorescent intensity data were acquired during the extension time. Specificity of the PCR reaction was assessed by the presence of a single peak in the dissociation curve after the amplification and through size estimation of the amplified product. For gene dosage measurements, the relative quantification-monocolor analysis from the LightCycler Software 4.0 package (Roche) was used. This program compares the ratio of a target sequence to a reference DNA sequence, i.e. the sequence in the gametoclonal sample with the sequence in a diploid wild type sample. PCR and normalized calculations were repeated in at least three independent samples from each genotype, rendering an averaged estimation ( \pm standard deviation) of target gene dosage in the haploids. Primers for the reference sequence are provided in Table 2 .

\section{Results and discussion}

\section{Chromosome counts}

After DAPI and hematoxylin staining of chromosomes in independent labs, 9 were found in ESP and FRA, and 27 chromosomes in ITA (Figure 1), confirming their

Table 2 Primer sequences for each gene

\begin{tabular}{ll}
\hline EST name & Primer sequence \\
\hline C04035D02 & 3'-CCCAAGCCAGATTTGATCAAGGGTC-5' \\
& 3'-TGGATGTCACACCACTCCAGCAGAT-5' \\
IC0AAA36DF07 & 3'-AGCGCTCTTAAATCAACCCGTC-5' \\
& 3'-GGATACTGCTGACTGATGTTGC-5' \\
IC0AAA34BC06 & 3'-TGATTCTCGTTGAGGGTCCTC-5' \\
C34004E09 & 3'-GCAATTCGCCACTTCAGGGTAA-5' \\
IC0AAA74CE10 & 3'-ATGAAGTGTGAGGGTTGCGTTG-5' \\
& 3'-TTCGGTCATGGTCTTCAGAGGT-5' \\
C06013D07 & 3'-CGGTTCAAGAGAGGAGTTGTT-5' \\
& 3'-GATGCAACACATCAGGTGGGAT-5' \\
C08012E04 & 3'-TGGATTTGCTTGGTGCACACTG-5' \\
3'-GCTGTTTCTTCAACTACAGATCC-5' & 3'-AGTGGGATTGGTGTGGCAAAC-5' \\
IC0AAA56DH07 & 3'-ACCTACTGGAAATCTGAAGACC-5' \\
\hline
\end{tabular}

C04035D02 was used as reference gene. 


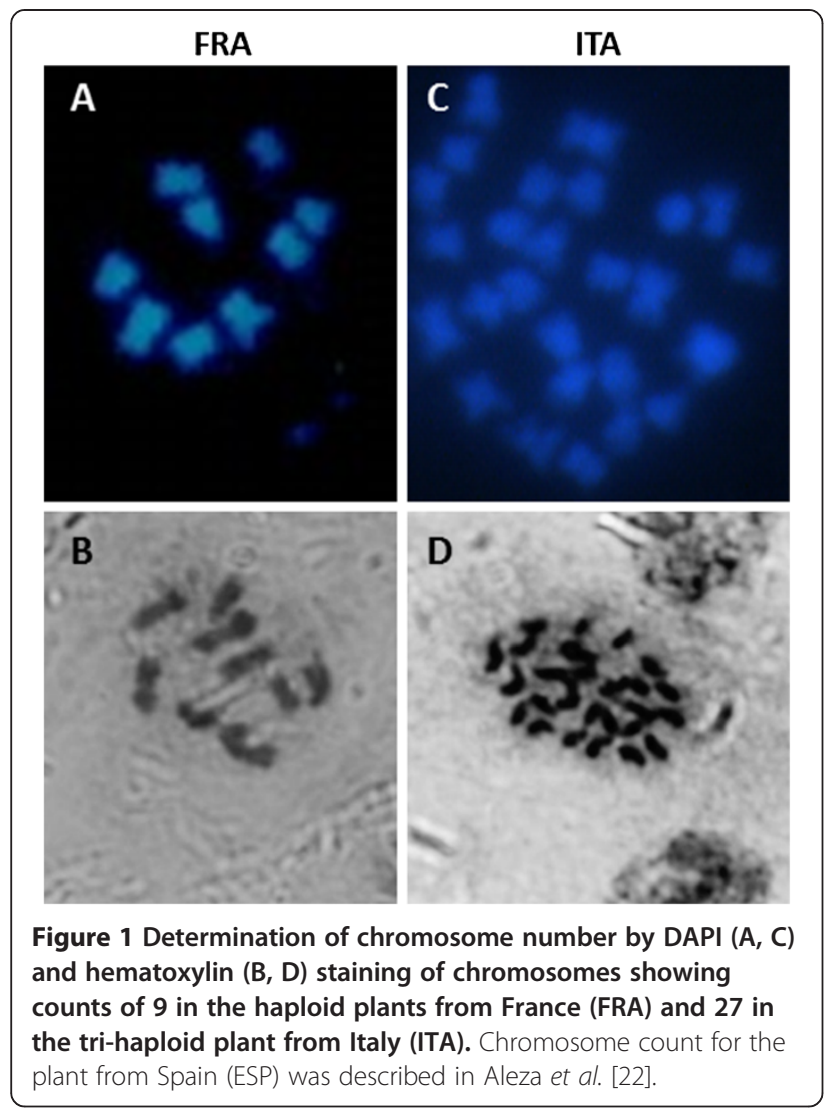

haploidy and tri-haploidy, respectively. They were further confirmed by flow cytometry (Additional file 1: Figure S2).

\section{SSR marker analysis}

A total of 237 SSR markers were selected, in many cases from previous mapping exercises, to represent as broad and unbiased coverage of the citrus genome as possible, and plant materials were genotyped (Table 1). No SSR alleles were detected in the gametoclones that were not present in diploid Clementine. At 232 loci the three gametoclones had one SSR allele also found in diploid Clementine. The gametoclones had the same allele as diploid Clementine at 45 of the 47 loci tested at which Clementine appeared homozygous. At two "anomalous" loci, the Clementine allele was observed in one or more of the gametoclones, and no allele was observed in the others. These two loci segregated for a null (no amplification) allele in a Clementine hybrid population, so these markers are also consistent with all gametoclones having complete, homozygous genomes. The gametoclones contained one of the two Clementine alleles at 183 of the 187 loci that were heterozygous in diploid Clementine. For three loci, the same two PCR products amplified from diploid Clementine were also observed in one or more of the gametoclones. Segregation of one of these loci was studied in a Clementine hybrid population and it was shown that these two PCR products segregated as a single Mendelian unit. This pattern could be caused by a tandem duplication of the amplified region, or by annealing of one PCR primer to nearly adjacent sites in the template DNA. Segregation of the other two loci has not been examined, but they could be explained possibly by a similar mechanism. Only one SSR locus revealed anomalous results in FRA, while the remainder revealed only a single allele product at all other loci surveyed.

\section{Array-CGH experiment}

In order to detect putative genomic deficiencies, genomic DNA from ITA, ESP and FRA genotypes and the diploid wild type was labelled and hybridized to a $20 \mathrm{~K}$ citrus cDNA microarray [34] by array-CGH, a procedure that previously proved to be useful for the structural prediction of large genomic deletions in Citrus clementina [32]. Those ESTs showing a haploid/diploid signal ratio of 0.3 or lower with a maximum P-value of 0.05 for any of the genotypes were selected for further analysis. From 13 ESTs fulfilling these conditions, two of them were annotated as putative $\mathrm{Cu} / \mathrm{Zn}$-superoxide dismutase copper chaperones, which are the 5'end (C34004E09) and 3'end (KN0AAA2CB01) of the same citrus cDNA (Table 3). Under-represented ESTs were found in the three gametoclonal genotypes in a number ranging from 4 in ESP to 8 in ITA with 4 of them jointly found in two different genotypes.

\section{Gene dosage experiment}

Seven of these ESTs were chosen for gene dosage evaluation by real-time PCR. Gene dosage measurements performed in this way confirmed the hybridization data presented in Table 3, except in two cases (Figure 2). Real-time PCR quantification failed to amplify ESTs C06013D07 and IC0AAA56DH07 that exhibited, respectively, microarray hybridization signal ratios of 0.23 and 0.30 in ITA, indicating that microarray data of these two ESTs was most likely affected by nonspecific crosshybridization.

Since a gene dosage around one is expected for those genes that are neither enriched nor reduced upon haploidization, the estimation of gene dosages lower and higher than one in certain ESTs argues for the occurrence of genomic rearrangements during the haploidization procedure, or alternatively the segregation of hemizygotic genes, that are present exclusively in one of the two alleles. A schematic overview of these and other genomic explanations for the observed deviations in gene dosage is presented in Figure 3. In this Figure, the standard case of genes not affected by the haploidization procedure, with both haploids having identical alleles and therefore a constant gene dosage around one is exemplified in panel A. In the hemizygotic model, a gene or DNA fragment is 
Table 3 Underrepresented ESTs after array-CGH of haploid genomic DNA

\begin{tabular}{|c|c|c|c|c|c|c|c|c|}
\hline \multirow[t]{2}{*}{ EST } & \multirow[t]{2}{*}{ Accession } & \multicolumn{2}{|c|}{ Genotype ITA } & \multicolumn{2}{|c|}{ Genotype FRA } & \multicolumn{2}{|c|}{ Genotype ESP } & \multirow[t]{2}{*}{ Description } \\
\hline & & Normalized ratio $\left(^{*}\right)$ & P-value $(* *)$ & Normalized ratio $(*)$ & P-value $(* *)$ & Normalized ratio $(*)$ & P-value $(* *)$ & \\
\hline ICOAAA36DF07 & DY274520 & $2.08(0.98-3.45)$ & -- & $0.04(0.03-0.06)$ & $1.8 \mathrm{E}-04$ & $0.04(0.01-0.09)$ & $5.0 \mathrm{E}-02$ & No annotation available \\
\hline ICOAAA34BC06 & DY273568 & $0.34(0.26-0.63)$ & $1.4 \mathrm{E}-02$ & $0.24(0.17-0.31)$ & $1.5 \mathrm{E}-03$ & $0.31(0.28-0.40)$ & $1.0 \mathrm{E}-02$ & No annotation available \\
\hline C34004E09 & FC930172 & $0.95(0.87-1.05)$ & -- & $0.13(0.09-0.20)$ & 1.7E-03 & $0.98(0.92-1.05)$ & -- & $\mathrm{Cu} / \mathrm{Zn}$-superoxide dismutase copper chaperone \\
\hline KN0AAA2CB01 & DY256847 & $1.00(0.64-1.92)$ & -- & $0.07(0.01-0.35)$ & $3.4 \mathrm{E}-02$ & $0.78(0.39-2.19)$ & -- & $\mathrm{Cu} / \mathrm{Zn}$-superoxide dismutase copper chaperone \\
\hline C31204A07 & FC874254 & $1.04(0.85-1.20)$ & -- & $0.21(0.10-0.40)$ & $1.2 \mathrm{E}-02$ & $2.33(1.78-3.87)$ & -- & Thaumatin-like protein isoform 3 \\
\hline ICOAAA74CE10 & DY290159 & $0.22(0.18-0.30)$ & $1.3 \mathrm{E}-03$ & $1.65(1.30-2.07)$ & $1.4 \mathrm{E}-02$ & $0.21(0.18-0.27)$ & $6.3 \mathrm{E}-03$ & Nematode resistance-like protein \\
\hline KNOAAK2BA02 & DY259689 & $0.14(0.07-0.19)$ & $3.6 \mathrm{E}-03$ & $1.74(1.24-2.59)$ & $3.9 \mathrm{E}-02$ & $0.21(0.14-0.26)$ & $1.4 \mathrm{E}-02$ & No annotation available \\
\hline C06013D07 & CX298593 & $0.23(0.11-0.40)$ & 1.1E-02 & $1.26(1.11-1.42)$ & $3.5 \mathrm{E}-02$ & $1.37(1.29-1.45)$ & $1.1 \mathrm{E}-02$ & No annotation available \\
\hline C31810G10 & FC924855 & $0.18(0.10-0.50)$ & 1.7E-02 & $1.81(1.35-2.64)$ & $3.8 \mathrm{E}-02$ & $1.35(0.89-2.68)$ & -- & Copine I-like protein \\
\hline C08012E04 & CX301690 & $0.28(0.17-0.54)$ & $1.8 \mathrm{E}-02$ & $1.87(1.40-2.58)$ & $2.3 \mathrm{E}-02$ & $1.28(0.83-2.99)$ & -- & No annotation available \\
\hline ICOAAA56DH07 & DY282523 & $0.30(0.12-0.63)$ & 4.0E-02 & $1.66(1.43-2.13)$ & $1.2 \mathrm{E}-02$ & $1.72(1.17-2.13)$ & -- & No annotation available \\
\hline ICOAAA89CG08 & DY295961 & $0.27(0.14-0.45)$ & $1.6 \mathrm{E}-02$ & $0.43(0.28-0.99)$ & -- & $1.52(0.87-2.42)$ & -- & No annotation available \\
\hline KNOAAB2CE09 & DY258014 & $0.07(0.03-0.14)$ & 7.0E-03 & $1.59(1.16-2.14)$ & 4.0E-02 & $0.21(0.11-0.66)$ & -- & SJCHGC09076 protein \\
\hline
\end{tabular}

(*) Normalized haploid to diploid signal ratio. In bold, signal ratios lower than 0.3. Replicates with lowest and highest values are shown in brackets.

${ }^{(*)}$ Only Pvalues lower or equal to 0.05 are shown. 


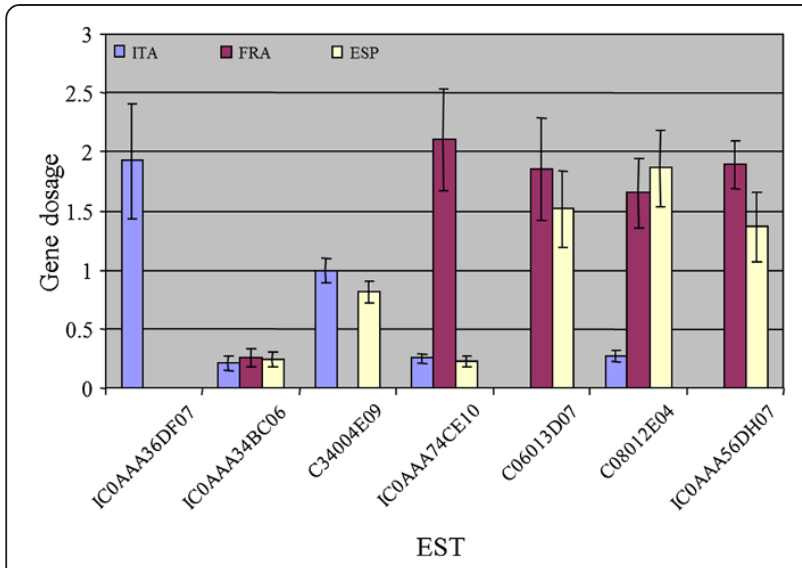

Figure 2 Relative gene dosage of selected ESTs in the three haploids by real-time PCR. Values are average and standard deviation of three determinations. Gene dosage is relative to the value of the diploid variety.

absent in one of the alleles leading to gene dosages equal to zero in haploids carrying the deleted allele. In the diploid parental, the PCR amplification of hemizygotic genes is originated from only one allele, as the second allele is absent (Figure 3B). The relative enrichment of the gene in haploid individuals inheriting the full allele causes a twofold increase in gene dosage, whereas haploids carrying the null allele have a value close to zero. In this work, IC0AAA36DF07, C06013D07 and IC0AAA56DH07 showed such a hemizygous-like behavior. In the deletion model, as outlined in Figure 3C, the gene is deleted during haploidization procedures producing a null allele that is not present in the diploid. EST C34004E09, for example, was not detectable in FRA but its content in ITA and ESP individuals was close to one. These data could be explained by a genomic deletion mechanism occurring during the haploidization process. Under this model, haploids losing the gene during the haploidization do not show PCR amplification signal, but those haploids inheriting an intact allele show a relative gene dosage similar to the original diploid. Finally, the remaining three ESTs analyzed by real-time PCR show low gene dosage values higher than zero in the three haploids (IC0AAA34BC06) or in at least one of them (ICOAAA74CE10 and C08012E04). Three different structural models were postulated to explain these observations. In the polymorphic tandem repeats model (Figure 3D), a tandemly-repeated gene found respectively ' $x$ ' and ' $y$ ' times in the two alleles, show a gene dosage value responding to the equations $(2 \cdot x) /(x+y)$ and $(2 \cdot y) /(x+y)$ in the two alternative haploids. Thus, a 5 -fold ratio in the number of repeats would produce relative gene dosages of $10 / 6$ and $2 / 6$ in the resultant haploids, certainly similar to the observed values. Alternatively, polymorphic variations in the primer binding sequence on the gene might cause allele-specific modifications of PCR

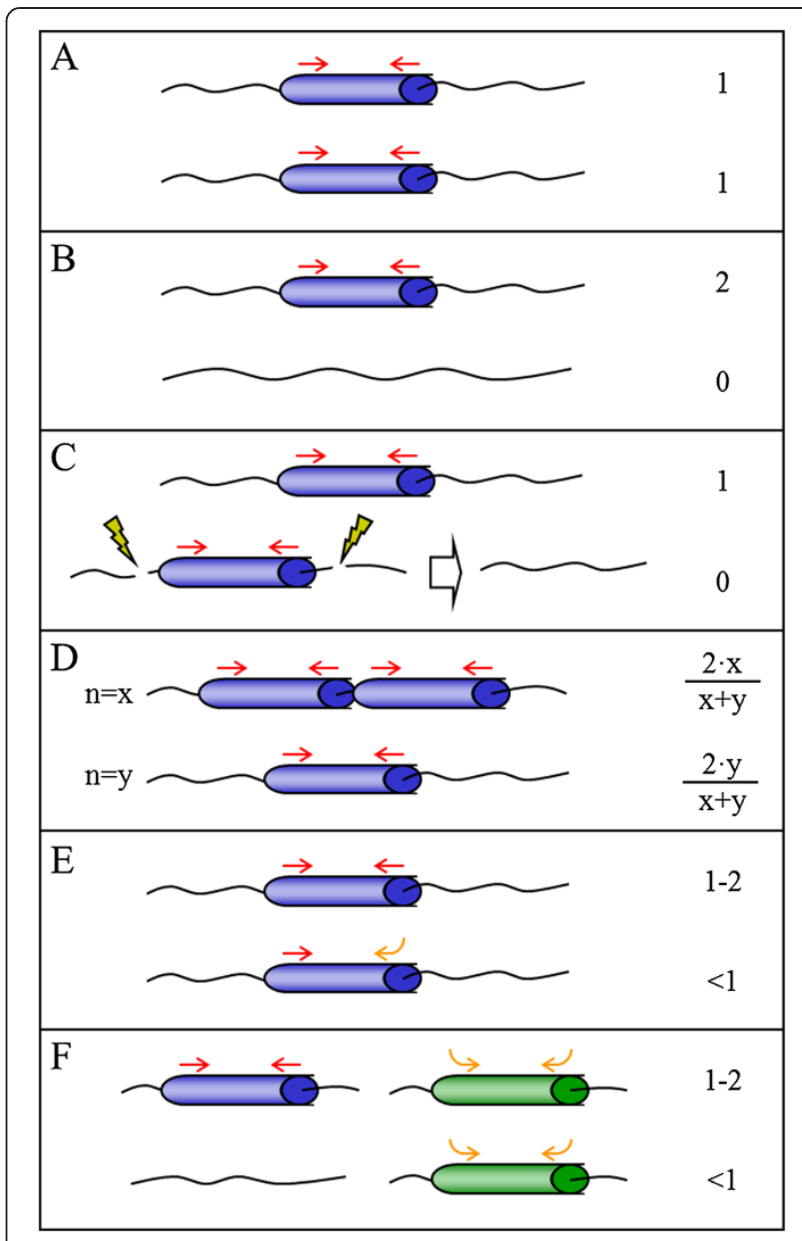

Figure 3 Proposed models for the genomic mechanisms resulting in lower gene representation in the gametoclones. Genes are depicted as blue and green cylinders and primers as red (specific) and orange (non-specific) arrows. Yellow flashes label deletion limits and the white arrow indicates conversion of standard to null allele. In each panel up and down drawings represent two alleles of a given locus in the diploid variety. The number or equation on the right is the relative gene dosage estimated for a haploid line inheriting the corresponding allele located on the same level. Gene dosages are always one for the diploid line. For further explanations see the text. (A) Standard case; (B) Hemizygotic model; (C) Technical deletion model; (D) Polymorphic tandem repeats model; (E) Polymorphic sequence model; (F) Hemizygotic model and cross-reaction.

efficiency leading to variable gene dosages (Figure 3E, polymorphic sequence model). Another source of misestimation of gene dosage might result from the combination of hemizygosis and non-specific cross-reaction of the primers, as presented in Figure 3F that originate altered determinations of gene dosage in the resulting haploid genotypes. Thus, the results confirm that ITA, ESP and FRA genomes do not carry important fragment deletions or rearrangements, and the few genomic differences observed between the diploid and haploid ge- 
notypes can be explained to a large extent by the natural heterozygosity of the diploid parental.

\section{Conclusion}

In this study, chromosome counting confirmed that ESP and FRA were haploid and ITA tri-haploid. Among a total of 237 SSR markers, most were selected from previous mapping exercises and represented broad and unbiased coverage of the citrus genome. 231 markers detected a single allele in ITA, ESP and FRA; each allele also existed in the diploid Clementine genome. Of the six SSR loci with anomalous results, segregation in Clementine was studied for three loci and in these cases the anomalous results in the haploids were shown to be caused by similar anomalies in Clementine. The array-CGH experiment revealed that only $13 \mathrm{cDNAs}$ had anomalous results among more than 20,000 cDNAs on the array. After real-time PCR of 7 of these genes, only four showed a gene dosage close to zero in one or two candidates, so no relevant gene loss was detected in any of the three genomes. Consequently array-CGH, in addition to all other characterization methods employed, provided compelling evidence that haploidization of citrus through in situ parthenogenesis induced by irradiated pollen followed by in vitro embryo culture, or by pollen embryogenesis, does not generate substantial genome rearrangements. Therefore, these three gametoclones can be used, with no concerns regarding their genomic integrity, for genetic studies as well as for citrus improvement, for example, through dihaploidization. In addition, it is noteworthy that the conclusions reached in this study, that haploidization does not disrupt the natural citrus genome structure, provided the major basis for the selection of the target citrus genome for producing the reference sequence for the international citrus research community [22].

\section{Additional file}

Additional file 1: Figure S1. Two homozygous plants of Citrus clementina Hort. ex Tan., cV. Nules from France (FRA) and Italy (ITA). The third, from Spain (ESP), was described in Aleza et al. [22]. Figure S2. Flow cytometry analyses of DNA content for the plants from France (FRA) and Italy (ITA).

\section{Competing interests}

The authors declare that they have no competing interests.

\section{Authors' contributions}

MAG provided one of the gametoclones (ITA), contributed to the design of the project, and wrote the first draft of the manuscript. PA provided one of the gametoclones (ESP), and contributed to its characterization. EC extracted DNA and analyzed microarray data. CC performed the SSR analysis at UF-CREC and contributed to the design of the project, and to writing and revision of the manuscript. $\mathrm{BC}$ contributed to the development and characterization of one of the gametoclones (ITA). GC contributed to the SSR genotyping at INRA. DD performed chromosome counts and flow cytometry at CIRAD. XD, WG and QX performed chromosome counts at HAU. CF, KK, and MR performed SSR genotyping at UCR; MR contributed to the design of the project and manuscript revisions. JJ contributed to the characterization of ESP gametoclone. FL contributed to the SSR genotyping at INRA, and provided genetic linkage maps of diploid Clementine. MM contributed to SSR genotyping at CCSM, and to the design of the project. VI prepared plant material and was involved in revising the manuscript. MAN performed real-time PCR. GR designed and carried out microarray experiments, visualized the models regarding gene expression in the haploids and contributed to drafting and revising the manuscript. LN contributed the ESP gametoclones and provided plant materials to the international collaborators, as well as contributions to the manuscript. PO contributed one of the gametoclones (FRA), contributed to the design of the project, as well as to the manuscript. MT contributed to the design of the work and collaborated in the drafting and revising of the manuscript. FG contributed to the design and coordinated the project, on behalf of the International Citrus Genome Consortium, drafted and revised the manuscript, and is corresponding author. All authors read and approved the manuscript.

\section{Acknowledgements}

Work at the Centro de Genómica (IVIA) was supported by the Spanish Ministerio de Ciencia e Innovación-FEDER grants PSE-060000-2009-008 and IPT-010000-2010-43, and grants [AGL2011-26490] from the Ministry of 'Economía y Competivida-Fondo Europeo de Desarrollo Regional (FEDER)' and [Prometeoll/2013/008] from the Generalitat Valenciana, Spain. Work performed by Elena Blázquez, Ángel Boix, Isabel Sanchis is gratefully acknowledged. Work at the UF-Citrus Research and Education Center was supported by grants from the Florida Citrus Production Research Advisory Council, and the Citrus Research and Development Foundation, on behalf of the Florida citrus growers. Work at the CIRAD was supported by the French Genomic ANR 2008 CITRUSSEQ project. Work at IAC was supported by INCT Citrus by FAPESP and CNPq.

\section{Requesting deposition of data}

The array data have been submitted to ArrayExpress. Experiment name: Molecular Characterization of Three Gametoclones of Citrus clementine. ArrayExpress accession: E-MEXP-3926. Specified release date: 2104-01-10.

\section{Author details}

${ }^{1}$ Università degli Studi di Palermo, Dipartimento di Scienze Agrarie e Forestali, Viale delle Scienze, 11, Palermo 90128, Italy. ${ }^{2}$ IVIA, Centro de Genómica, Moncada, Valencia, Spain. ${ }^{3}$ University of Florida, Citrus Research and Education Center, Lake Alfred, FL, USA. ${ }^{4}$ CIRAD, Département "Systèmes Biologiques" Unité de Recherche 'Multiplication Végétative' Montpellier, Paris, France. ${ }^{5}$ Huazhong Agricultural University, Wuhan, Hubei, China. ${ }^{6}$ University of California, Department of Botany and Plant Sciences, Riverside, CA, USA. ${ }^{7}$ INRA, UR GEQA, San Giuliano, France. ${ }^{8}$ Instituto Agronômico de Campinas, Centro APTA Citros Sylvio Moreira, Cordeirópolis, SP, Brazil. ${ }^{9}$ IVIA, Centro de Proteccion Vegetal y Biotecnologia, Moncada, Valencia, Spain. ${ }^{10}$ USDA-ARS, Southeastern Fruit and Tree Nut Research Laboratory, Byron, GA, USA.

Received: 17 April 2013 Accepted: 24 August 2013

Published: 10 September 2013

\section{References}

1. Germanà MA: Anther culture for haploid and doubled haploid production. Special issue: "In vitro Ploidy Manipulation in the Genomics Era". Plant Cell Tiss Organ Cult 2011, 104:283-300. doi:10.1007/s11240-010-9852-z.

2. Germanà MA: Gametic embryogenesis and haploid technology as valuable support to plant breeding. Special issue "Plant Biotechnology in support of the Millenium Development Goals". Plant Cell Rep 2011, 30:839-857

3. Germanà MA: Haploidy. In Citrus Genetics, Breeding and Biotechnology. Edited by Khan I. Oxfordshire, UK: CABl; 2007:167-196.

4. Germanà MA: Doubled haploid production in fruit crops. Plant Cell Tiss Org Cult 2006, 86:131-146.

5. Germanà MA: Protocol of somatic embryogenesis from Citrus spp. anther culture. In Protocol of Somatic Embryogenesis-Woody Plants. Edited by Jain SM, Gupta PK. Netherlands: Dordrecht Springer; 2005:191-207. ISBN 1-4020-2984-5.

6. Germanà MA: Haploids and doubled haploids in Citrus spp. In Doubled Haploid Production in Crop Plants. A Manual. Edited by Maluszynsky M, Kasha KJ, Forster BP, Szaejko I. Netherlands: FAO-IAEA, Dordrecht Kluwer Academic Publisher; 2003:303-308. 
7. Germanà MA: Haploidy in Citrus. In In vitro Haploid Production in Higher Plants. Volume 5th edition. Edited by Jain SM, Sopory SK, Veilleux RE. Dordrecht, The Netherlands: Kluwer Academic Publishers; 1997:195-217.

8. Chiancone B, Tassoni A, Bagni N, Germanà MA: Effect of polyamines on in vitro anther culture of Citrus clementina Hort ex Tan. Plant Cell Tissue and Organ Culture. ISSN: 0167-6857. 2006, 87:145-153.

9. De Lange JH, Vincent AP: Studies on Citrus pollination using gamma irradiated pollen. South African Journal of Botany 1988, 54:257-264.

10. Froelicher Y, Bassene JB, Jedidi-Neji E, Dambier D, Morillon R, Bernardini GG, et al: Induced parthenogenesis in mandarin for haploid production: induction procedures and genetic analysis of plantlets. Plant Cell Rep 2007, 23:2007

11. Ollitrault P, Allent $V$, Luro F: Production of haploid plants and embryogenic calli of clementine (Citrus reticulata Blanco) after in situ parthenogenesis induced by irradiated pollen. Proceeding International Society Citriculture. South Africa 1996, 2:913-917.

12. Hidaka T, Yamada Y, Shichijo T: In vitro differentiation of haploid plants by anther culture in Poncirus trifoliata (L.) Raf. Japanese Journal Breeding 1979, 29:248-254.

13. Chen Z, Wang H, Liao H: The induction of Citrus pollen plants in artificial media. Acta Genetica Sinica 1980, 7:189-192.

14. Deng XX, Deng ZA, Xiao SY, Zhang WC: Pollen derived plantlets from anther culture of Ichang papeda hybrids No.14 and Trifoliate orange. In Proceedings of the International Society of Citriculture. Acireale, Italy; 1992:190-192.

15. Germanà MA, Chiancone B, Lain O, Testolin R: Anther culture in Citrus clementina: a way to regenerate tri-haploids. Aust J Agr Res 2005, 56:839-845. ISSN: 0004-9409.

16. Germanà MA, Chiancone B: Improvement of the anther culture protocol in Citrus clementina Hort. ex Tan. Plant Cell Rep 2003, 22(3):181-187. ISSN 0721-7714.

17. Germanà MA, Wang YY, Barbagallo MG, lannolino G, Crescimanno FG: Recovery of haploid and diploid plantlets from anther culture of Citrus clementina Hort. ex Tan. and Citrus reticulata Blanco. J Hort Science 1994, 69:473-480

18. Germanà MA, Reforgiato G: Haploid embryos regeneration from anther culture of 'Mapo' tangelo (Citrus deliciosa x C. paradisi). Advances in Horticultural Science 1997, 11:147-152

19. Germanà MA, Crescimanno FG, De Pasquale F, Wang YY: Androgenesis in 5 cultivars of Citrus limonL. Burm. f. Acta Horticulturae 1991, 300:315-324.

20. Froelicher $Y$, Ollitrault P: Effects of the hormonal balance on Clausena excavata androgenesis. In Proc. of the First Inter. Symp. on Citrus Biotechnology. 535th edition. Edited by Goren R, Goldschmidt EE. Eilat, Israel: Acta Horticulturae; 2000:139-146.

21. Cao H, Kumar Biswas M, Lu Y, Hamdy Amar M, Tong Z, Xu Q, Xu J, Guo W Deng $X$ : Doubled haploid callus lines of Valencia sweet orange recovered from anther culture. Plant Cell Tiss Organ Cult 2011, 104:415-423.

22. Aleza P, Juarez J, Hernandez M, Pina JA, Ollitrault P, Navarro L: Recovery and characterization of a Citrus clementina Hort ex Tan Clemenules haploid plant selected to establish the reference whole Citrus genome sequence. BMC Plant Biol 2009, 9:110. doi:10.1186/1471-2229-9-110.

23. Guo WW, Deng XX, Shi YZ: Optimization of electrofusion parameters and interspecific somatic hybrids regeneration in Citrus (in Chinese with English summary). Acta Bot Sin 1998, 40:417-424.

24. Froelicher $Y$, Dambier D, Costantino G, Lotfy S, Didout C, Beaumont $V$, Brottier P, Risterucci AM, Luro F, Ollitrault P: Characterization of microsatellite markers in Citrus reticulata Blanco. Molecular Ecology Notes 2008, 8(1):119-122

25. Luro F, Costantino G, Billot C, Froelicher Y, Morillon R, Ollitrault P, Terol J, Talon M, Gmitter FG Jr, Chen C: Genetic maps of Clementine mandarin and intergeneric hybrid Clementine $X$ Poncirus using genomic and EST microsatellite markers. Plant \& Animal Genome XV, San Diego, CA 2007, 13-17:2007

26. Luro F, Costantino G, Argout $X$, Froelicher $Y$, Terol J, Talon M, Wincker $P$, Ollitrault P, Morillon R: Transferability of the EST-SSRs developed on Nules clementine (Citrus clementina Hort ex Tan) to other Citrus species and their effectiveness for genetic mapping. BMC Genomics 2008, 9:287.

27. Chen C, Zhou P, Choi YA, Huang S, Gmitter FG: Mining and characterizing microsatellites from citrus ESTs. Theor App/ Genet 2006, 112:1248-1257.
28. Chen C, Bowman KD, Choi YA, Dang PM, Rao MN, Huang S, Soneji JR, McCollum TG, Gmitter FG Jr: EST-SSR genetic maps for Citrus sinensis and Poncirus trifoliata. Tree Genetics and Genomes 2008, 4:1-10.

29. Chalhoub BA, Thibault S, Laucoou V, Rameau C, Höfte H, Cousin R: Silver staining and recovery of AFLP amplification products on large denaturing polyacrylamide gels. BioTech 1997, 22:216-220.

30. Barkley NA, Roose ML, Krueger RR, Federici CT: Assessing genetic diversity and population structure in a citrus germplasm collection utilizing simple sequence repeat markers (SSRs). Theor Appl Genet 2006, 112:1519-1531.

31. Oetting WS, Lee HK, Flanders DJ, Wiesner GL, Sellers TA, King RA: Linkage analysis with multiplexed short tandem repeat polymorphisms using infrared fluorescence and M13 tailed primers. Genomics 1995, 30:450-458.

32. Rios G, Naranjo MA, Iglesias DJ, Ruiz-Rivero O, Geraud M, Usach A, Talon M: Characterization of hemizygous deletions in Citrus using array-comparative genomic hybridization and microsynteny comparisons with the poplar genome. BMC Genomics 2008, 9:381.

33. Dellaporta SL, Wood J, Hicks JB: A plant DNA minipreparation: version II. Plant Molecular Biology Reports 1983, 1:19-21.

34. Martinez-Godoy MA, Mauri N, Juarez J, Marques MC, Santiago J, Forment J, Gadea J: A genome-wide $20 \mathrm{~K}$ citrus microarray for gene expression analysis. BMC Genomics 2008, 9:318.

doi:10.1186/1471-2229-13-129

Cite this article as: Germana et al:: Cytological and molecular characterization of three gametoclones of Citrus clementina. BMC Plant Biology 2013 13:129.

\section{Submit your next manuscript to BioMed Central and take full advantage of:}

- Convenient online submission

- Thorough peer review

- No space constraints or color figure charges

- Immediate publication on acceptance

- Inclusion in PubMed, CAS, Scopus and Google Scholar

- Research which is freely available for redistribution 